\title{
Development Design and Research of Elevator Advertisement Projection Products Driven by PSET
}

\author{
Kang $\mathrm{Hu}$ \\ Art and Design College \\ Wuhan University of Science and Technology \\ Wu Han, China \\ 108893770@qq.com
}

\author{
Rong Mao \\ Art and Design College \\ Wuhan University of Science and Technology \\ Wu Han, China \\ 527865332@qq.com
}

\begin{abstract}
Under the influence of new internet media advertisement, as a part of integrated marketing communication, the application of new technology and method in domestic modern advertising industry is becoming more and more important. Based on the PSET analysis method, this paper has clarified the gap of PSET (policy-society-economy-technology) in elevator advertisement. Taking the whole elevator advertisement projection development process as an example, this paper analyzes the existing elevator advertisement operation environment, discovers the problem and innovation point, puts forward the concept of innovative design of elevator advertisement projection, to validate its feasibility and perfect it based on the innovative technology method. On the basis of this, the paper determines the molding structure and design direction of the product and gives the designing plan, optimizes the plan and develops a set of stable innovation products, then further establishes the research system flow of the elevator advertisement projection innovation design, and provides lessons and reference for the development and design of innovative products in related industries.
\end{abstract}

Keywords-elevator advertising; projection; innovation; research

\section{INTRODUCTION}

At present, the development of the domestic elevator advertising product is market demand-oriented, to achieve the product function and market positioning according to the existing technology, Constantly seek new technical means, designing and creating new elevator advertising media iterative products is the development direction of current mainstream building advertising enterprises. It is also more important to analyze the PSET analysis method in the prophase of product development. Cao Guoen et. al [1] through the deep analysis of the SET gap put forward the design principles of the homebased care interactive product system, and then established the platform architecture of the home-based care interactive product system. In the book of Create Breakthrough Products, Jonathan Cagan [2] also elaborated the importance on how to use the PSET analytical products and PSET analytical method in IPND, in this book, the gap analysis method of PSET (political-socio-economic-technology) mode is used, through fuzzy prophase, the elevator advertising user analysis in PSET mode, PSET product opportunity key gap depth analysis these three stages to identify elevator advertising product opportunities and to clear product direction. On this basis, the new technology and method are used to realize the function positioning of the product, and the development and design of the elevator advertisement projection is completed

\section{ANALYSIS OF ELEVATOR ADVERTISEMENT GAP IN PSET} MODE

\section{A. Fuzzy prophase}

The development and design of the elevator advertisement projector has experienced the initial stage of the fuzzy prophase and in this stage, we understand the type of the existing new media in the elevator, and initially fuzzily understand the development direction of the product. New media in the elevator are mainly LCD building TV, elevator frame billboards, electronic poster machine, as a new advertising media, it has been favored and used by many advertisers including finance, IT, communication, home appliance, technology and so on., but advertising companies or other agencies generally take a paste and replacement method or artificial electronic painting method when releasing the advertisement to the building crowd, the former uses the disposable material and the latter is relatively more cumbersome. Therefore, combined with the new technology, to inject more technology and internet thinking into the elevator new media development. The analysis to the elevator advertising new media technology and user in the PSET mode [3], can identify the market gaps and product innovation in the current mode. Figure 1 shows the general elevator inside media and elevator projection new media, the fuzzy prophase value opportunity comparison conducts a screen on to the opportunities of the products, summed up the value opportunities of elevator projection new media, and as a research direction, conducted an in-depth analysis on this direction gap. 
TABLE I

User elements of elevator advertising products

\begin{tabular}{|c|c|c|c|c|}
\hline \multicolumn{5}{|c|}{ User elements of elevator advertising products } \\
\hline Appearane & \multicolumn{4}{|c|}{ Product visual design } \\
\hline Frame & \multicolumn{4}{|c|}{ Product Operation Product Maintenance } \\
\hline Structural & \multicolumn{4}{|c|}{ UI and information architecture } \\
\hline Range & \multicolumn{4}{|c|}{ Function Description Product content } \\
\hline Strategic & \multicolumn{4}{|c|}{ User target product target } \\
\hline DEPTH & 1 & 2 & 3 & 4 \\
\hline
\end{tabular}

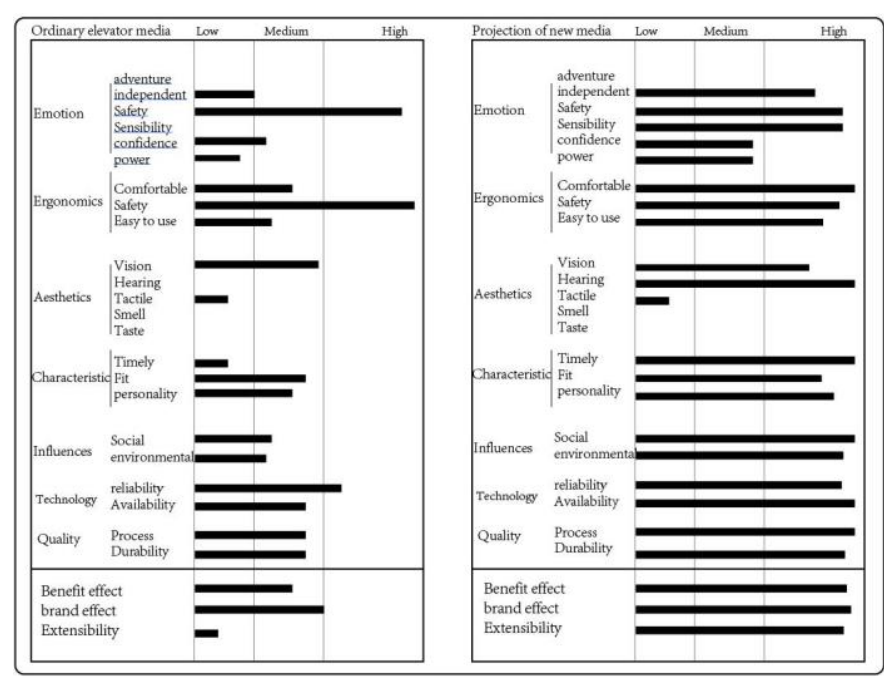

Fig. 1 Fuzzy prophase value opportunity comparison

\section{B. Analysis of elevator advertisement users in 2 PSET mode}

Elevator advertising mainly composed of residential elevators and commercial elevators two parts, mostly distributed in residential areas and commercial offices, shopping malls and other places. Advertise users are mainly divided into commercial users and individual users, the first is advertising companies, property media and so on, the second is ordinary consumers. The efficiency and value of advertising communication are mainly influenced by these two kinds of users, and the analysis of the relationship between user experience and elevator advertising products in PEST mode is shown in Table 1, progressively shown from the performance layer to the strategic level:

1.The product visual effect is good, the elevator is the only route for users who taking the elevator, the visual impact force and the compulsive readability of the media, which has novel design, vivid color as well as the attractive appearance, is quite big;

2.The information structure is clear, the enclosed elevator space, the exclusive audience groups, each frame of the elevator frames can form an independent bull's-eye spread;

3. Economy: The existing elevator frame advertising needs to be replaced frequently, the media on-painting, downpainting, the artificial economic efficiency is low.
Functional innovation, product function and technological innovation, to change the existing advertising model at one point, users will produce a strong interest in it, which change the efficiency of the transmission mode.

\section{PSET Product opportunity key gap depth analysis}

In the PSET analysis mode, the critical gap depth analysis in the design of advertisement projection in elevator becomes the key element in the innovation design. As shown in Figure 2 , the value opportunity of the key gap of product opportunity is transformed into the overall and representative product design guideline on the basis of PSET. In view of the insufficiency of elevator advertising in the existing mode, elevator advertising products should have the following driving forces:

Policy-driven: the state is creating a mass entrepreneurship and innovation policy, both social and enterprise layers are stimulated, the market competition is improved to a new height and new level.

Social development: At present, elevator advertising product development is market demand-oriented, the competition is increasingly fierce, and many commercial advertising companies are seizing the building elevator advertising this piece of cake.

Economic level: in 2016, China's advertising industry market value of nearly trillion yuan, of which the traditional media market shares still accounted for nearly $80 \%$, is several times of the new media. However, from the trend of development, the development of new media is rapid, advertisers marketing spending is gradually shifting.

Technical level: The development of internet technology has brought great changes to the production process and transmission mode of the elevator advertising content. Constantly seek new technical means, designing and creating new elevator advertising media iterative products is the development direction of current mainstream building advertising enterprises.

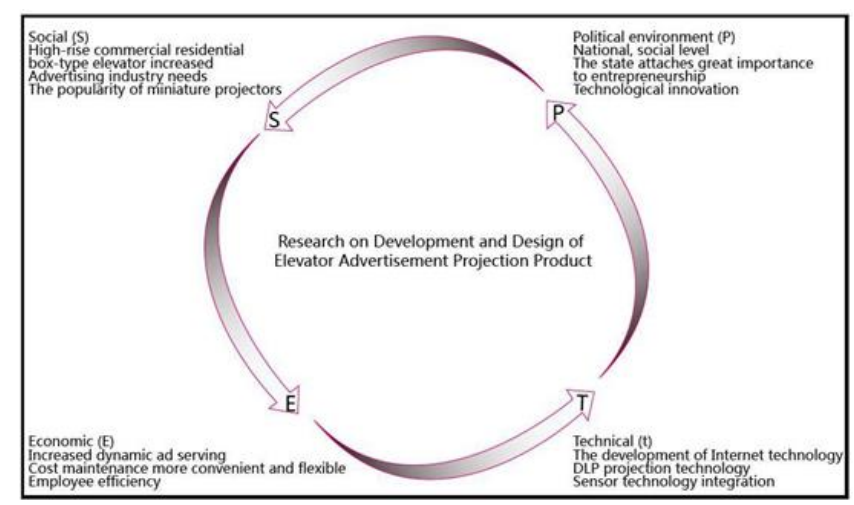

Fig. 2 PSET Factors of new media in elevator projection

According to the analysis of PSET factors, the development of elevator advertising products shows the trend of new technologies, new means and new methods. Ordinary elevator frame advertising and LCD building TV has not been able to meet the speed and efficiency of advertising transmission, in order to solve these problems, this paper puts forward the 
concept of advertising projection. Based on INPD product design and development process [4], the application of projection technology in advertisement will make the performance of elevator advertisement change in an unprecedented way. To perfect elevator advertisement projection development and the iteration will make up the gap of the elevator door advertisement.

\section{TECHNOLOGY INNOVATION DRIVE ELEVATOR ADVERTISEMENT PROJECTION SYSTEM}

Based on the analysis of the PSET gap of elevator advertisement, it is found that the mainstream of the market is pasted frame-type advertising and elevator TV ads, the former has limited visual effect of advertisement communication, the latter is too bulky and the vision drop point is not ideal. The elevator advertising projector concept proposed here, most of the micro-projector are currently using the DLP projection technology, only find this technical can support this concept, through the optical projection can project the images onto the inside door of elevator.

In the case that someone is in the elevator, the elevator door is closed, the projection interior sensor will sense the running status and record the data and situation, then project the images onto the elevator door, which is shown in Figure 4. Here the projector increased the speed sensor and the air pressure sensor and the control module to monitor the elevator operation status, the projection interior $\mathrm{WiFi}$ transmission technology transmits the data information through the mobile terminal equipment, to achieve user feedback and advertising replacement on-painting maintenance work.

\section{A. Functional principles}

The elevator advertisement projector uses the projector + control module + The induction equipment + the mobile communication module to build the advertisement platform which adapts the elevator environment.

The whole package is packaged as a whole (as shown in Fig. 4) installed inside the elevator, taking the elevator door as the projection screen, through the induction equipment to monitor the elevator movement status and elevator door movements, control the projector reproduction, the elevator door closed or elevator start to run, that is, open the projector (as shown in Figure 4 left) and start to project, and when the elevator door opened or elevator stop operation, to immediately close the projection (as shown in Figure 4 right), the projection can display different content based on the different floors, and can be remote control through mobile communication, no field operation, the playback content can be selected and updated remotely.

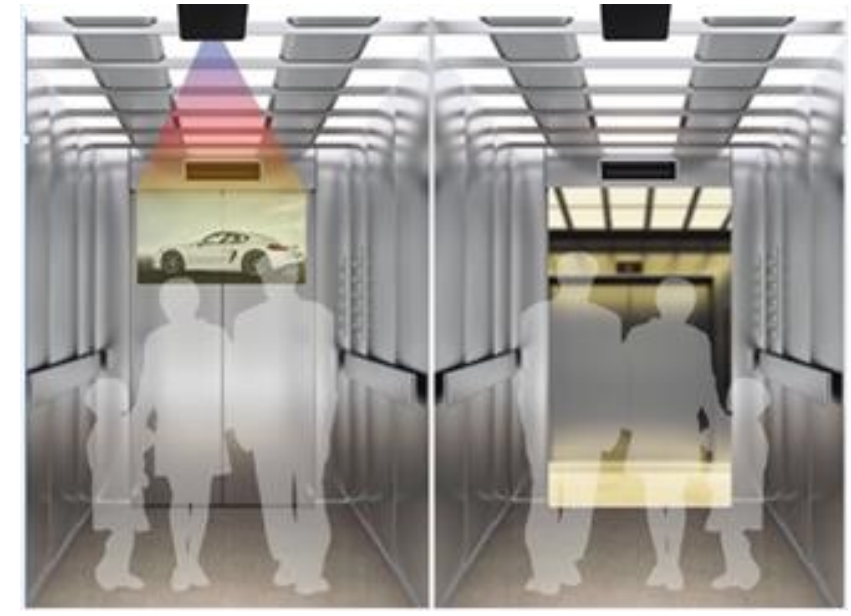

Fig. 3 Elevator advertising projection operation scenario

\section{B. Technology Roadmap}

The new type elevator advertising projector uses DLP technology can meet the requirements for advertising playback in brightness and screen, the principle is that the cold light source emitted by the UHP bulb through the condensation lens, through rod (light rod) to make the light homogenization, the light after processing through a color wheel (color Wheel), divide the light into RGB three colors (or RGBW and many other colors), using BSV LCD splicing technology lens to filter light conduction, and then project the color from the lens onto the DMD chip, The final reflection is imaged on the projection screen through the projection lens. The entire system structure framework is shown in Figure 5:

The state sensor, which is a data processing unit used to collect the acceleration in the gravity direction of the elevator, and used to conduct filtering and mean processing of the information collected by the accelerometer; The state determination unit, which is used to determine the operation state of the elevator according to the data output from the data processing unit; And the control unit, which is used to control the DMD device in the DLP projection module to achieve the starting and stopping of the projection picture according to the result determined by the state determination unit; Data transmission module, which is used for the running state and information transmission between the background and equipment; DLP projection device and sound efficiency system, which is used for images projecting and sound output.

When the elevator stops, the state determination unit determines that the elevator operation is static, the player outputs the black screen to the projection module, all its pixel RGB values are 0 , and the controller controls every micro-chip in the DMD device, so that the reflected light does not shoot out from the lens.

In the elevator movement process, the state determination unit determines the elevator operation is raising or lowering, the player outputs the normal image picture to the projection module, the controller controls each microchip in the DMD device to reflect the RGB value of each pixel in the screen, and the images are shot out from the lens. 


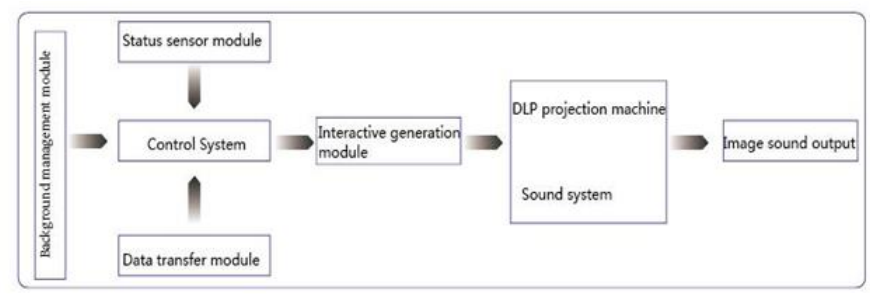

Fig. 4 Advertising projection system structure frame diagram

The whole set of projection system has an open API, can provide a fire-new personalized media advertising experience, devices can build a more intelligent advertising product launch platform on the basis of the internet of things.

\section{PROGRAM DESIGN}

\section{A. Design positioning}

Elevator advertising projector, the appearance of simple and generous, needs to solve the complex operating environment in the elevator, can accurately put the dynamic audio ads to the focus area of the crowd visual point on elevator door. To solve the pollution caused by bonded poster on the elevator environment, can also replace the replaceable type poster, improves the maintainability of advertisement equipment inside elevator, to play the maximum value of the elevator advertising [5].

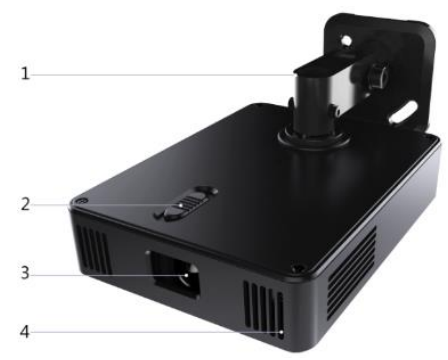

Fig. 5 Projection

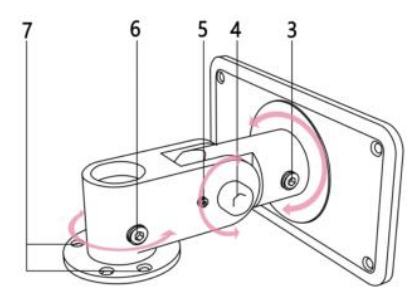

Fig. 6 Hanger analysis Diagram

\section{B. Appearance structure optimization design}

Elevator projection advertising machine needs to meet the complex operating environment in the elevator. In addition to considering the internal structure, the product size also needs to take into account the product installation process, as well as the environmental impact when using, to ensure the normal operation of the product. In this process, we should consider the impact of human factors, to ensure that the product has an optimal human-machine use environment. The entire product appearance design as shown in Fig. 6, mainly includes optical machine, focusing, PCB motherboard, cooling fan, hanger interface, USB, switch, power interface, etc. The operation environment of the elevator is relatively more complex, in order to guarantee the stable and normal operation of the projection, the hanger is designed as shown in the Figure 7, the hanger can perform three-axis angle adjustment and be fastened by the M8 and M4 hexagon screws to achieve the installation and fixation of the whole product. The hanger can guarantee a suitable height and projection angle, will not block the screen in the case of that there's a lot of persons in the elevator [5].

As shown in Fig. 8, the miniature projection inside the product has a separate data processing module, which is used for filtering and mean value processing to the data collected by the accelerometer to monitor the operation state of the elevator, uses the algorithm for data processing to realize the screen turn-on and turn-off. DLP Optical Machine module has a high temperature when it opens, thus there is need to design a heat dissipation hole for it, cooperates with the heat dissipation chip sink duct can block foreign bodies entering, as is shown on the figure above.

\section{Material technology optimization}

After the structural design is completed, by doing the structure palm validation, to verify from opening mould to the test mode. As shown in the pictures: respectively is the product structure, palm and mold pictures. After several times of mold testing and repairing, the final product is assembled successful, as shown in Figure 8. The ABS material injection molding was used in this process, and in the subsequent prototype using process, we found that, because of the unique operating environment, the strength of which is low, and the toughness and seismic capacity is weaker. PC and fiberglass enhancements were added to the next production, thus effectively avoiding such problems.

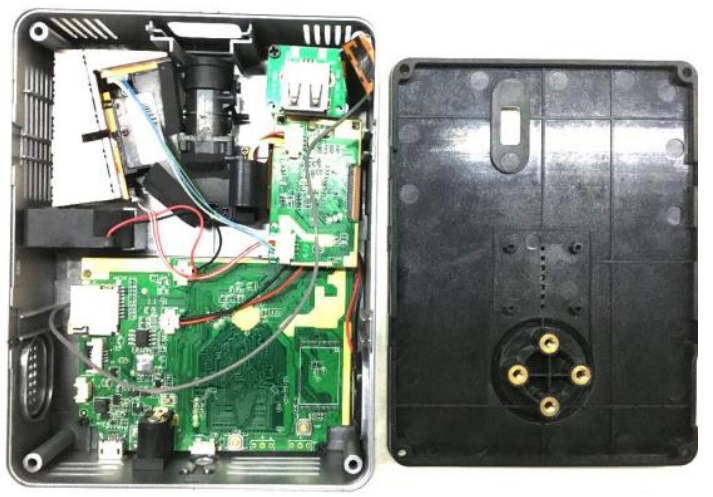

Fig. 7 Prototype diagram of the trial production

\section{MOBILE END APP DESIGN}

Elevator advertising projection mobile terminal APP interactive design is designed cooperated with elevator projection advertising machine functional positioning requirements, combined with the self-operating system of the projection and used Internet technology, to achieve the administrator of the equipment management of humancomputer interaction. Advertising company operators and users can, through the APP, easily manage maintenance and operation of equipment to achieve their own interests' demands [7]. As shown in Figure 9, given the business efficiency, the 
advertising company administrator can quickly learn and master the equipment use skills, the entire APP design is concise, and the projection function setting is divided into the six blocks with different colors, click on different color block. The main function of the APP module is divided into painting, equipment settings, screen adjustment, etc., for example, click the orange color block, you can update the content of the projection screen. Click the screen adjustment, we can adjust the projected size of the screen to adapt to different elevator space and so on. Therefore, the projection operators can easily achieve the equipment operation supervision, in the maintenance process, can also greatly simplify the previous advertisement update step. The design of the APP effectively realizes the connection between the advertisement projection and the Internet, realizes the systematization of the equipment, makes up the insufficiency of the traditional operation and maintenance, and injects the internet thinking for the new media development in the future elevator.

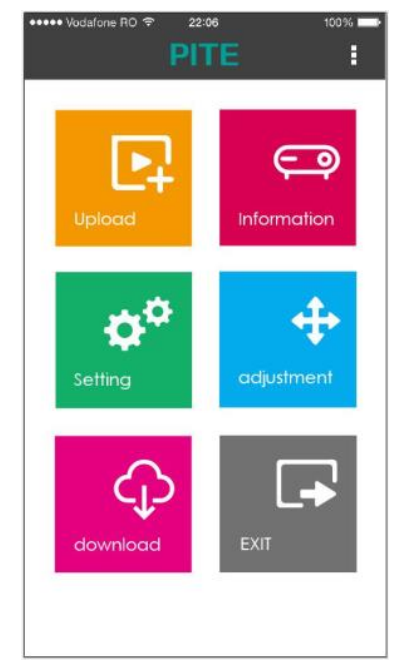

Fig. 8 Web site and App interface

\section{CONCLUSION}

This article takes the commercial advertisement product of the elevator as the research object, from the angle of the PSET analysis method, discovers that there is a gap in the elevator frame advertising. The research considers that the advertisement projection in elevator has great commercial value, and finds the accurate positioning of the product through the user market analysis. Under the technology-driven leading, achieved the product advertising function, in the realization of these functions, from the view of policy, social, economic and technical value, based on the product's practical function, structure, appearance, man-machine interaction and other aspects of innovative design, the products are finally created, which achieves the goal of new product development, resulting in economic benefits, fills the new media blank in the elevator. This paper summarizes a new product development process based on PSET, and provides reference for the development and design of other advertising products.

\section{REFERENCES}

[1] Cao Guoen, Zhang Xin, Deng Rong et. al, "Design of Home-Based Care Interactive Product System Based on SET Analysis Method," Mechanical Design, Dec 2014.

[2] Jonathan Cagan /Craig M. Vogel, Create Breakthrough Products,'FT Press, Nov 2001.

[3] Cai Wen, "Product Design of Electronic Medicine-Taking Equipment Based on User-Oriented," Mechanical Design, Sept 2015.

[4] Li Mengjun, Xu Kaiqiang. Modeling Design of Angle Grinder Based on INPD and SD, Mechanical Design, Feb 2017.

[5] Dai Sato, Noriko Kawakami, "Look at the Design from Inside to outside," translated by Deng Chao, Beijing Times Chinese Press, March 2015.

[6] Ding Yulan, "Man-Machine Engineering," "Beijing Institute of Technology Press," April 2011.

[7] Zhao Dawei . "Internet Thinking Lonely-Sword," China Machine Press, 2014 . 